Carmen López Esteban (ed.)

\title{
Aulas Innovadoras en la Formación de los Futuros Educadores de Educación Secundaria
}

Modelos y Experiencias en el Máster en Profesor de Educación Secundaria Obligatoria y Bachillerato, Formación Profesional y Enseñanzas de Idiomas 


\section{AQUILAFUENTE, 290}

(C)

Ediciones Universidad de Salamanca

y los autores

$1^{\text {a }}$ edición: julio, 2020

ISBN: 978-84-1311-323-4 (impreso)

978-84-1311-322-7 (PDF)

DOI: http://dx.doi.org/10.14201/0AQ0290

Depósito legal: S 134-2020

Ediciones Universidad de Salamanca

Plaza San Benito, s/n

E-37002 Salamanca (España)

http://www.eusal.es

eus@usal.es

Realizado en UE-Made in EU

Diseño y maquetación:

Helvética edición y diseño

Impresión y encuadernación:

Gráficas LOPE

C/ Laguna Grande, 2, Polígono «El Montalvo Il»

www.graficaslope.com

37008 Salamanca. España

Todos los derechos reservados.

Ni la totalidad ni parte de este libro puede reproducirse ni transmitirse sin permiso escrito de Ediciones Universidad de Salamanca

Obra sometida a proceso de evaluación mediante sistema de doble ciego

Ediciones Universidad de Salamanca es miembro de la UNE

Unión de Editoriales Universitarias Españolas

www.une.es

\section{CEP. Servicio de Bibliotecas}

AULAS innovadoras en la formación de futuros educadores de Educación Secundaria: modelos y experiencias en el Máster en Profesor de Educación Secundaria Obligatoria y Bachillerato, Formación Profesional y Enseñanzas de Idiomas / Carmen López Esteban (ed.).

-1a edición: julio, 2020.—Salamanca : Ediciones Universidad de Salamanca, [2020]

420 páginas : ilustraciones (blanco y negro).-(Aquilafuente ; 290)

Incluye referencias bibliográficas

Abstracts en español e inglés

1. Profesores (Enseñanza secundaria)-Formación. 2. Enseñanza-Innovaciones.

I. López Esteban, María Carmen, 1963-, editor.

373.5.011.3-051 


\section{Resumen}

La lengua como código puede aprenderse como terminología surgida del trabajo metalingüístico de los gramáticos, pero como discurso vivo merece una reflexión profunda para ver de qué manera acomodamos, como docentes, esas categorías teóricas de manera que sean objetos de manipulación útil para la comunicación. Es decir, no se trata de prescindir de la gramática como objeto de conocimiento sino de incluirla en el contexto de la práctica docente y discente y superar, así, la frustación, desinterés y apatía que las clases de lengua suscita en las jóvenes generaciones de estudiantes. En esta línea se sitúa el trabajo que presentamos con la aportanción de una tarea, como ejemplo de que la modernización de las clases de gramática puede llevarse a cabo lejos de la manida memorización de reglas.

GRAMÁTICA, DISCURSO, PAISAJE LINGÜÍSTICO, COMPETENCIA COMUNICATIVA

\section{Abstract}

Language as a code can be learned as terminology arising from the metalinguistic work of grammarians, but as living discourse it deserve a deep reflection to see how we accommodate, as teacher, those theorical categories so that they are objects of manipulation useful for communication. That is, it is not a question of dispensing with grammar as an object of knowledge but of including it in the context of learning and teaching practice, and thus overcoming the frustration, disinterest and apathy that Spanish subject arouses in the younger generations of students. Along these lines, the work we present with the contribution of a task, as an example of that the modernization of grammar subject can be carried out far from the rules memorization procedure. 


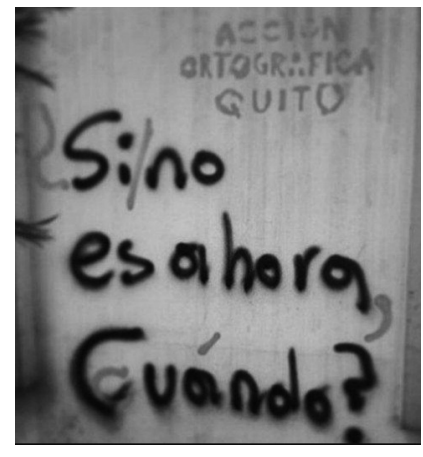

En trabajOS anteriores (Álvarez-Rosa, 2019a; 2019b y 2019c; Álvarez-Rosa, Marcet Rodríguez y Ramos Ahijado, 2018) se apuntaba la necesidad de incorporar a los estudios universitarios de grado y postgrado, en especial a aquellos conducentes para la docencia, prácticas pedagógicas en las que se llevaran a cabo actividades pautadas y de adquisición progresiva para la concienciación del desarrollo de la competencia comunicativa (tanto en su vertiente oral como escrita), debido a la falta de instrumentos y conocimiento práctico que nuestros estudiantes y futuros profesores tienen sobre aspectos relevantes de la comunicación en su contexto formal.

El motivo de este desconocimiento puede deberse al tratamiento que de la enseñanza de la lengua se practica en los estadios educativos anteriores, a pesar de que desde la década de los noventa del pasado siglo Xx se insiste desde los currículos, de cualquier etapa, la adaptación del enfoque comunicativo. Así, el Real Decreto 126/2014, de 28 de febrero, por el que se establece el currículo básico de la Educación Primaria y el Real Decreto 1105/2014, de 26 de diciembre, por el que se establece el currículo básico de la Educación Secundaria y del Bachillerato apuntan como objetivo principal para la asignatura troncal de Lengua Castellana y Literatura:

* Este trabajo es fruto de la ayuda a la investigación otorgada por la Institución Gran Duque de Alba (IGDA)/ Diputación Provincial de Ávila.

** La imagen ha sido extraída de https://bit.ly/2RwRiKC. A los lectores de este trabajo les redirigimos a este enlace para que observen, con la nitidez que ofrece la fotografía en color, las correcciones realizadas por el grupo de Acción Ortográfica de Ecuador. 
el desarrollo de la competencia comunicativa del alumnado, entendida en todas sus vertientes: pragmática, lingüística, sociolingüística y literaria. [Asimismo, d]ebe también aportar las herramientas y los conocimientos necesarios para desenvolverse satisfactoriamente en cualquier situación comunicativa [...]. Esos conocimientos son los que articulan los procesos de comprensión y expresión oral [sic] por un lado, y de comprensión y expresión escrita [sic] por otro.

Considerado este objetivo como continuador de la enseñanza mínima del segundo ciclo de Educación Infantil (Real Decreto 1630/2007, de 19 de diciembre), en el área "Lenguajes: Comunicación y representación" ya se especifica:

el lenguaje oral es especialmente relevante en esta etapa, es el instrumento por excelencia de aprendizaje, de regulación de la conducta y de manifestación de vivencias, sentimientos, ideas, emociones, etc. La verbalización, la explicación en voz alta, de lo que están aprendiendo, de lo que piensan y lo que sienten, es un instrumento imprescindible para configurar la identidad personal, para aprender, para aprender a hacer y para aprender a ser. Con la lengua oral se irá estimulando, a través de interacciones diversas, el acceso a usos y formas cada vez más convencionales y complejas.

En el segundo ciclo de Educación infantil se pretende que niños y niñas descubran y exploren los usos de la lectura y la escritura, despertando y afianzando su interés por ellos. La utilización funcional y significativa de la lectura y la escritura en el aula, les llevará, con la intervención educativa pertinente, a iniciarse en el conocimiento de algunas de las propiedades del texto escrito y de sus características convencionales cuya adquisición se ha de completar en el primer ciclo de Primaria.

Ante esta realidad curricular, a un lado y a otro del océano (Lomas, 2014), con una clara adhesión a una didáctica comunicativa del lenguaje, ¿por qué se insiste desde las aulas en el aprendizaje de la norma del código orientado al conocimiento académico y cuyo valor cobra sentido en el intercambio de beneficios escolares y no en su uso como herramienta de comunicación?, ¿por qué se sigue insistiendo en mecanismos de enseñanza anacrónicos y, por ende, ineficaces para el estudiante de hoy? Con estas preguntas no queremos dar a entender que la gramática sea una realidad inútil. Ni mucho menos. En todo caso, consideramos que es el enfoque adoptado lo que repercute negativamente en la predisposición de los estudiantes ante las clases de lengua materna. En esta línea, pero como mayor rotundidad, Mantecón (1989: 74) afirmaba que la gramática, como ciencia, era útil y 
necesaria; sin embargo, "los malos o desorientados gramáticos o los profesores impreparados o las malas gramáticas [son] los causantes de los desastres pedagógicos o didácticos".

Con el intento de modernizar la praxis discente-docente en las aulas, integrando el conocimiento reflexivo y útil de la lengua ${ }^{1}$ en la competencia comunicativa que se reconoce en el área de Lengua y Literatura, se plantea una propuesta de tarea cuya base es un modo continuo de interacción que fomenta la observación, reflexión y práctica de la gramática en el discurso. Así, una apuesta por trabajar de manera holística la gramática nos ha hecho salir a buscar tal acción fuera del aula para, por un lado, demostrar al alumno que lo aprendido en el centro escolar se puede reconocer en la calle y, por el otro, ofrecer al docente recursos cotidianos que pueden reinterpretarse para la didáctica de la lengua materna, en general, y de la gramática, en particular. En este sentido cobra especial relevancia el paisaje lingüístico de la ciudad.

\section{A vueltas con el paisaje lingüístico}

El paisaje lingüístico de un territorio, esto es, signos escritos visibles en espacios públicos (por ejemplo, carteles de comercios, anuncios, placas de edificios gubernamentales...) ayudan al investigador a determinar la lengua predominante del lugar, el estatus de poder de colectivos lingüísticos asentados en él o determinar el índice de vitalidad etnolingüística (Landry y Bourhis, 1997). Por ello, desde hace unos años a esta parte, los estudios sobre paisaje lingüístico han pivotado en torno al ámbito de la Sociolingüística², principalmente.

\footnotetext{
${ }^{1}$ Desde el Real Decreto 1105/2014 se plantea el conocimiento de la lengua como "el aprendizaje progresivo de las habilidades lingüísticas, así como la construcción de competencias en los usos discursivos del lenguaje a partir del conocimiento y la reflexión necesarios para apropiarse de las reglas ortográficas y gramaticales imprescindibles, para hablar, leer y escribir correctamente en todas las esferas de la vida". Esta misma concepción se manifiesta en el Real Decreto 126/2014: "[el c]onocimiento de la lengua responde a la necesidad de reflexión sobre los mecanismos lingüísticos que regulan la comunicación, y se aleja de la pretensión de utilizar los conocimientos lingüísticos como un fin en sí mismos para devolverles su funcionalidad original: servir de base para el uso correcto de la lengua".

2 Dada la amplia bibliografía reconocida sobre el tema y porque nos extralimitaríamos del propósito de este trabajo, referenciaremos aquellas salidas a colación de nuestro discurso.
} 
Sin embargo, la utilidad didáctica que un paisaje lingüístico puede proporcionar va más allá de lo reseñado anteriormente. Dado que este paisaje es, por esencia, representaciones escritas de sujetos reales para un contexto determinado, podemos contemplar la posibilidad de convertir estos signos públicos en una herramienta útil del aprendizaje integrador y actualizado de la gramática en el discurso, ya que "can create a context for motivation as language is linked to real places and activities", como acertadamente apunta Malinowski (2014) en un entorno de inmersión para el aprendizaje de una lengua extranjera.

Esta consideración no es desdeñable para la enseñanza de la materna. El paisaje lingüístico urbano supone una fuente directa de inputs y es una oportunidad excelente para comprender mejor los aspectos relacionados con la lengua y su uso, además de ser recurso para concienciar sobre el valor de la competencia pragmática y discursiva de los textos publicados o para conformar al estudiante como agente crítico de las producciones verbales de su entorno (Sayer, 2009). En definitiva, "linguistic landscape projects may be a powerful tool in the language classroom, allowing students to consider how people use language within local settings" (Chestnut et al., 2013: 114) y piezas útiles para promover la reflexión activa sobre la lengua.

En el apartado siguiente, siguiendo esta creencia, destinaremos nuestros esfuerzos en plantear una tarea en la que se evidencia la posibilidad de integrar coherentemente los conceptos gramática y discurso en el marco de la metodología activa.

\section{Tarea para el aula: El paisaje lingüístico y la acción correctora}

El enfoque por tareas como opción metodológica está más que superada en el marco de la enseñanza de una segunda lengua, como confirma el hecho del número de publicaciones que se han sucedido desde la década de los años 80 (Long, 1985; Richards, Platt y Weber, 1986; Estaire y Zanón, 1990 y 1994; Zanón, 1999; Nunan, 2011; entre otros). Sin ánimo de reincidir en la definición del concepto "tarea", solo destacamos sus características principales desde el punto de vista pedagógico:

- Representativa de procesos de comunicación real

- Identificable como unidad de trabajo en el aula 
- Destinada a un aprendizaje de la lengua

- Organizada en torno a un objetivo, estructura, secuencia de trabajo concretas y evaluación

- Promotora del aprendizaje autónomo del estudiante

- Vinculada al aprendizaje de lengua en el aula con su uso fuera de ella

Echando un vistazo a estos rasgos, no cabe duda de su aplicabilidad en la metodología de la enseñanza de la lengua que estamos proponiendo desde las páginas iniciales de este trabajo. Como ejemplo, presentamos la unidad temática titulada Ayudantes de la RAE en la que los alumnos -insistimos en su aplicación en diferentes niveles educativos siempre que se adecue al nivel cognitivo del grupo destinatario- simulan ser miembros de una agrupación anexa a la Real Academia Española que pretende registrar, identificar y limpiar los errores lingüísticos detectados en los signos públicos de su ciudad para redactar, desde la reflexión metalingüístico-discursiva, un dosier informativo.

Para el diseño de esta unidad temática, nos hemos basado en el modelo propuesto por Estaire y Zanón (1990), que contempla la interrelación existente entre los distintos modelos del proceso.

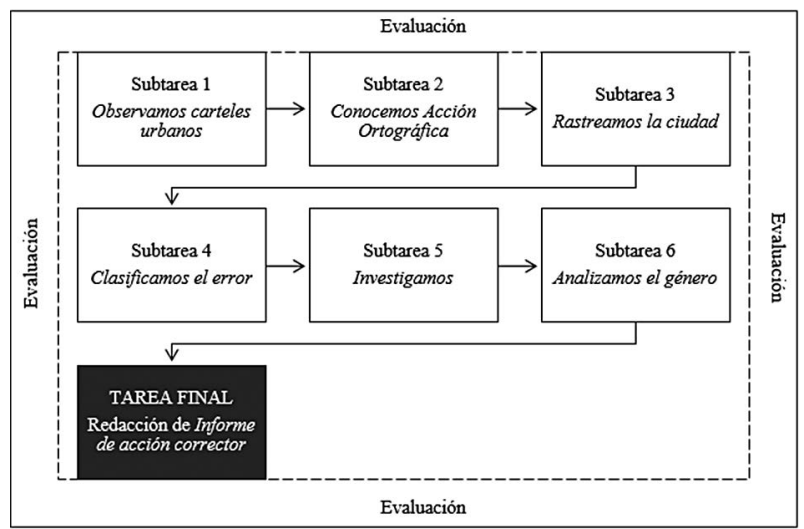

Cuadro 1. Organización de la unidad temática Ayudantes de la RAE. Adaptado de Estaire y Zanón (1990) 
A continuación detallamos las subtareas y tarea final reseñadas en el cuadro 1, atendiendo a su descripción, agrupación, los resultados de aprendizaje, materiales y rúbrica de (auto)evaluación.

\section{Subtarea 1: "Observamos carteles urbanos"}

Descripción de la subtarea: Consiste en poner a los estudiantes en contacto con carteles públicos de su ciudad con el fin de que los reconozcan como signos lingüísticos. Se les proyectará una serie de imágenes de muy diversa índole (anuncios, publicidad de comercios, carteles, señalizaciones verticales, etc. $)^{3}$ en las que se pueden detectar o no algún error gramatical, léxico, ortográfico, etc. El docente fomentará la acción de descubrimiento con preguntas orientadoras del tipo: ¿qué tienen en común todas estas imágenes?, ¿se puede establecer alguna clasificación?, ¿están todas escritas de acuerdo a la norma? Con ello se dará paso a la fase inicial de ejecución reflexiva: el estudiante formulará hipótesis para establecer un criterio taxonómico de estas imágenes.

Carácter: Individual/ en grupo

Resultados de aprendizaje:

- Presentar el paisaje lingüístico como signo

- Conectar el paisaje lingüístico con la gramática

- Aprender a organizar la información de acuerdo un criterio

- Fomentar el aprendizaje autónomo por descubrimiento

Materiales: Fotografías del paisaje lingüístico urbano, ordenador y proyector.

\footnotetext{
${ }^{3}$ Ejemplos de este banco de imágenes están recogidos en el anexo 1 del presente trabajo.
} 
Rúbrica de evaluación:

\begin{tabular}{|c|c|c|c|c|c|}
\hline $\begin{array}{l}\text { CRITERIOS PARA } \\
\text { LA EVALUACIÓN } \\
\text { DEL ALUMNO }\end{array}$ & NADA & $\mathrm{POCO}$ & ACEPTABLE & SATISFACTORIO & OBSERVACIÓN \\
\hline $\begin{array}{l}\text { ¿Participa en } \\
\text { la dinámica? }\end{array}$ & & & & & \\
\hline $\begin{array}{l}\text { ¿Observa } \\
\text { con interés? }\end{array}$ & & & & & \\
\hline $\begin{array}{l}\text { La clasificación } \\
\text { es coherente al } \\
\text { criterio establecido }\end{array}$ & & & & & \\
\hline $\begin{array}{l}\text { Expone sus opinio- } \\
\text { nes con claridad } \\
\text { y coherencia }\end{array}$ & & & & & \\
\hline $\begin{array}{l}\text { OBSERVACIONES } \\
\text { DEL PROCESO }\end{array}$ & \multicolumn{5}{|c|}{$\begin{array}{l}\text { El docente ha motivado a los estudiantes } \\
\text { al autodescubrimiento y a la reflexión } \\
\text { Efectividad del orden de aplicación de las actividades } \\
\text { Incidencias }\end{array}$} \\
\hline
\end{tabular}

\section{Subtarea 2: "Conocemos Acción Ortográfica"}

Descripción de la subtarea: Consite en dar a conocer el movimiento de Acción Ortográfica de diferentes países a través de documentos sonoros y visuales (noticiarios, páginas de redes sociales, artículos periódisticos...) ${ }^{4}$ con el fin de reflexionar sobre la necesidad de la correcta expresión lingüística desde el entorno más inmediato y, por tanto, no solo del académico.

Carácter: Grupal

Resultados de aprendizaje:

- Conocer el movimiento Acción Ortográfica

- Reflexionar sobre el uso adecuado de la lengua incluso en las situaciones de uso común

- Introducir el uso de las TIC

Materiales: Dispositivo electrónico con acceso a internet.

${ }^{4}$ En el anexo 2 se recoge una muestra significativa de los recursos que se pueden consultar. 
Rúbrica para la evaluación:

\begin{tabular}{|l|l|l|l|l|l|}
\hline $\begin{array}{l}\text { CRITERIOS PARA } \\
\text { LA EVALUACIÓN } \\
\text { DEL ALUMNO }\end{array}$ & NADA & POCO & ACEPTABLE & SATISFACTORIO & OBSERVACIÓN \\
\hline $\begin{array}{l}\text { Consulta las } \\
\text { páginas } \\
\text { propuestas }\end{array}$ & & & & & \\
\hline $\begin{array}{l}\text { Propone otras } \\
\text { páginas de } \\
\text { Consulta }\end{array}$ & & & & & \\
\hline $\begin{array}{l}\text { ¿Entiende la } \\
\text { causa de esta } \\
\text { acción? }\end{array}$ & $\begin{array}{l}\text { El docente ha motivado a los estudiantes } \\
\text { al autodescubrimiento y a la reflexión } \\
\text { Efectividad del orden de aplicación de las actividades } \\
\text { Incidencias } \\
\text { OBSERVACIONES PROCESO } \\
\text { DEL }\end{array}$ & & & \\
\hline
\end{tabular}

\section{Subtarea 3: "Rastreamos la ciudad"}

Descripción de la subtarea: El docente asigna a los estudiantes zonas de la ciudad cuyo paisaje lingüístico es relevante por su inadecuación en el uso de la lengua con el fin de que las raestree. Estos fotografiarán, al menos, dos signos y grabarán un vídeo por cada imagen, identificando y explicando el error. La horquilla de extensión de la grabación estará entre los 90 y 180 segundos.

Carácter: Individual

Resultados de aprendizaje:

- Fomentar la autonomía en el aprendizaje

- Impusar el empleo de la tecnología móvil con fines didácticos

- Favorecer el inicio a la investigación

- Incorporar los conocimientos previos relativos a la gramática

- Desarrollar la expresión oral

Materiales: Dispositivo móvil con opción a vídeo y cámara de fotos. 
Rúbrica para la evaluación:

\begin{tabular}{|l|l|l|l|l|l|}
\hline $\begin{array}{l}\text { CRITERIOS PARA } \\
\text { LA EVALUACIÓN } \\
\text { DEL ALUMNO }\end{array}$ & NADA & POCO & ACEPTABLE & SATISFACTORIO & OBSERVACIÓN \\
\hline $\begin{array}{l}\text { Las fotografías } \\
\text { SOn relevantes en } \\
\text { cuanto al objetivo } \\
\text { marcado }\end{array}$ & & & & & \\
\hline $\begin{array}{l}\text { ¿Identifica de } \\
\text { manera acertada } \\
\text { el error? }\end{array}$ & & & & & \\
\hline $\begin{array}{l}\text { La explicación res- } \\
\text { ponde favorable- } \\
\text { mente a los princi- } \\
\text { pios de adecua- } \\
\text { ción, cohesión } \\
\text { y coherencia }\end{array}$ & & & & \\
\hline $\begin{array}{l}\text { El vídeo cumple } \\
\text { Con el tiempo } \\
\text { exigido }\end{array}$ & & & & \\
\hline $\begin{array}{l}\text { OBSERVACIONES } \\
\text { DEL PROCESO }\end{array}$ & $\begin{array}{l}\text { El docente ha motivado a los estudiantes } \\
\text { al autodescubrimiento y a la reflexión } \\
\text { Efectividad del orden de aplicación de las actividades } \\
\text { Incidencias }\end{array}$ & & \\
\hline
\end{tabular}

\section{Subtarea 4: "Clasificamos el error"}

Descripción de la subtarea: A partir de la proyección de imágenes recopiladas de la subtarea anterior, los estudiantes tienen que valorar si la identificación del error realizada por el compañero ha sido correcta, y clasificarlo de acuerdo a un criterio (por ejemplo, puntuación, acentuación gráfica, composición léxica...). Previo a estas acciones, el autor de las fotografías ha de exponer el motivo que le llevó a hacerlas. Ahora bien, si la identificación y/o la causa no son satisfactorias, el docente orienta a la respuesta adecuada o desecha el signo por no ser pertinente.

Carácter: Grupal 
Resultados de aprendizaje:

- Identificar el error lingüístico

- Reflexionar sobre la norma

- Aprender a organizar la información en la inmediatez del discurso oral

- Fomentar la capacidad de síntesis

Materiales: Imágenes extraídas del paisaje lingüístico urbano, ordenador y proyector.

Rúbrica para la evaluación:

\begin{tabular}{|c|c|c|c|c|c|}
\hline $\begin{array}{l}\text { CRITERIOS PARA } \\
\text { LA EVALUACIÓN } \\
\text { DEL ALUMNO }\end{array}$ & NADA & POCO & ACEPTABLE & SATISFACTORIO & OBSERVACIÓN \\
\hline $\begin{array}{l}\text { Las fotografías } \\
\text { son relevantes en } \\
\text { cuanto al objetivo } \\
\text { marcado }\end{array}$ & & & & & \\
\hline $\begin{array}{l}\text { ¿Identifica de } \\
\text { manera acertada } \\
\text { el error? }\end{array}$ & & & & & \\
\hline $\begin{array}{l}\text { La explicación res- } \\
\text { ponde favorable- } \\
\text { mente a los princi- } \\
\text { pios de adecua- } \\
\text { ción, cohesión } \\
\text { y coherencia }\end{array}$ & & & & & \\
\hline $\begin{array}{l}\text { OBSERVACIONES } \\
\text { DEL PROCESO }\end{array}$ & \multicolumn{5}{|c|}{$\begin{array}{l}\text { El docente ha motivado a los estudiantes } \\
\text { al autodescubrimiento y a la reflexión } \\
\text { Efectividad del orden de aplicación de las actividades } \\
\text { Incidencias }\end{array}$} \\
\hline
\end{tabular}

\section{Subtarea 5: "Investigamos"}

Descripción de la subtarea: Si en la subtarea 2 el docente les da a conocer los movimientos de corrección llevados a cabo por ciudadanos anónimos, en esta les presenta páginas promovidas por la Real Academia Española o por especialistas de reconocido prestigio en el ámbito de las Letras ${ }^{5}$ y obras de referencia

\footnotetext{
${ }^{5}$ Blog de Lengua (en Twitter e Instagram: @blogdelengua), https://www.fundeu.es/, https:// www.rae.es/, principalmente.
} 
como la Nueva gramática básica de la lengua española (2011), la Ortografía escolar de la lengua española (2013) o Las normas académicas: últimos cambios (2011). A estas han de recurrir para reformular su explicación e introducir citas de autoridad como apoyo.

Carácter: Individual/ en grupo

Resultados de aprendizaje:

- Fomentar la búsqueda y rastreo de información en documentos de prestigio

- Desarrollar la reflexión metalingüística y poner en cuestión sus propias creencias

- Promover la capacidad de selección

Materiales: Obras de referencias o espacios de internet citados anteriormente, hojas en blanco o cuaderno.

Rúbrica para la evaluación:

\begin{tabular}{|l|l|l|l|l|l|}
\hline $\begin{array}{l}\text { CRITERIOS PARA } \\
\text { LA EVALUACIÓN } \\
\text { DEL ALUMNO }\end{array}$ & NADA & POCO & ACEPTABLE & SATISFACTORIO & OBSERVACIÓN \\
\hline $\begin{array}{l}\text { Criba la } \\
\text { información } \\
\text { consultada }\end{array}$ & & & & & \\
\hline $\begin{array}{l}\text { Cita } \\
\text { adecuadamente }\end{array}$ & & & & & \\
\hline $\begin{array}{l}\text { Referencia } \\
\text { adecuadamente }\end{array}$ & $\begin{array}{l}\text { Sabe valorar } \\
\text { sus creencias }\end{array}$ & $\begin{array}{l}\text { El docente ha motivado a los estudiantes } \\
\text { al autodescubrimiento y a la reflexión } \\
\text { Efectividad del orden de aplicación de las actividades }\end{array}$ & & \\
\hline $\begin{array}{l}\text { OBSERVACIONES } \\
\text { DEL PROCESO }\end{array}$ & \multicolumn{2}{l|}{} & & \\
\hline
\end{tabular}




\section{Subtarea 6: "Analizamos el género"}

Descripción de la subtarea: Consiste en llevar al aula un ejemplo real de un informe para que reconozcan y analicen las características formales y textuales de este género.

Carácter: Grupal/individual

Resultados de aprendizaje:

- Aprender las estructuras gramaticales propias de la descripción

- Reconocer las diferencias entre dos clases de descripción: objetiva e impresionista

- Conocer las características prágmaticas de la descripción

- Reconocer los aspectos textuales propios de este tipo de texto

Materiales: Informes reales, hojas en blanco o cuaderno.

Rúbrica para la evaluación:

\begin{tabular}{|l|l|l|l|l|l|}
\hline $\begin{array}{l}\text { CRITERIOS PARA } \\
\text { LA EVALUACIÓN } \\
\text { DEL ALUMNO }\end{array}$ & NADA & POCO & ACEPTABLE & SATISFACTORIO & OBSERVACIÓN \\
\hline $\begin{array}{l}\text { Examina con éxito } \\
\text { las estructuras } \\
\text { gramaticales (verbos } \\
\text { y tiempos) propias } \\
\text { de la descripción }\end{array}$ & & & & & \\
\hline $\begin{array}{l}\text { Detecta los rasgos } \\
\text { prágmáticos } \\
\text { (propósito y } \\
\text { destinatario) } \\
\text { del género }\end{array}$ & & & & & \\
\hline $\begin{array}{l}\text { Identifica los } \\
\text { aspectos textuales } \\
\text { propios de } \\
\text { la descripción }\end{array}$ & & & & & \\
\hline $\begin{array}{l}\text { Reflexiona sobre el } \\
\text { carácter objetivo del } \\
\text { género 'informe' }\end{array}$ & & & & & \\
\hline $\begin{array}{l}\text { OBSERVACIONES } \\
\text { DEL PROCESO }\end{array}$ & $\begin{array}{l}\text { El docente ha motivado a los estudiantes } \\
\text { al autodescubrimiento y a la reflexión } \\
\text { Efectividad del orden de aplicación de las actividades } \\
\text { Incidencias }\end{array}$ & & & \\
& & & & \\
\hline
\end{tabular}




\section{Tarea final:}

\section{"Redacción de Informe de acción correctora"}

Descripción de la tarea: Consiste en elaborar un dosier informativo de aquel error lingüístico detectado en los signos del paisaje urbano presentado anteriormente en grupo. Este incluirá ejemplos, referencias y citas que apoyen su exposición.

Carácter: Individual

Resultados de aprendizaje:

- Generar un informe de conceptualización gramatical

- Integrar las estructuras lingüisticopragmadiscursivas propias de la descripción

- Usar argumentos de autoridad

Materiales: las imágenes del paisaje lingüístico urbano, obras y/o páginas web de referencia, ordenador.

Rúbrica para la autoevaluación:

\begin{tabular}{|l|l|l|l|l|l|}
\hline $\begin{array}{l}\text { CRITERIOS } \\
\text { PARA LA AUTO- } \\
\text { EVALUACIÓN } \\
\text { DEL ALUMNO }\end{array}$ & NADA & POCO & ACEPTABLE & SATISFACTORIO & OBSERVACIÓN \\
\hline $\begin{array}{l}\text { He tenido en } \\
\text { cuenta los aspectos } \\
\text { lingüístico- } \\
\text { discursivos del } \\
\text { género 'informe' }\end{array}$ & & & & & \\
\hline $\begin{array}{l}\text { He consultado } \\
\text { fuentes fidedignas }\end{array}$ & & & & & \\
\hline $\begin{array}{l}\text { He incorporado las } \\
\text { referencias } \\
\text { webgráficas y/o } \\
\text { bibliográficas }\end{array}$ & $\begin{array}{l}\text { He aumentado mi } \\
\text { capacidad de } \\
\text { reflexión } \\
\text { metalingüística }\end{array}$ & $\begin{array}{l}\text { El discente ha cumplimentado la rúbrica de la autoevaluación } \\
\text { con objetividad } \\
\text { OB producto final evidencia los resultados de aprendizaje marcados } \\
\text { DEL PROCESO } \\
\begin{array}{l}\text { AUTOEVALUA- } \\
\text { CIÓN }\end{array}\end{array}$ & & & \\
\hline
\end{tabular}




\section{Conclusión}

Nuestra experiencia docente demuestra que el enfoque lúdico y el aprendizaje gramatical constituyen un tándem necesario para el impulso de la innovación en el aula de lengua, y que repercute en un redimiento comunicativo a todas luces efectivo. Ha de quedar atrás la memorización sobre los aspectos formales de la lengua abordadas de forma pasiva, ya que el rédito es un gran sentimiento de esterilidad. Las generaciones actuales, impacientes ante un clic, exigen implementar nuevas metodologías y recursos adecuados a la realidad del siglo XXI.

Por ello, si lo que pretendemos es que nuestros alumnos sean competentes, debemos suscitarles interés por lo que van a aprender, pues se implicarán en el aula y reflexionarán sobre lo aprendido. En este sentido, ha girado la propuesta presentada en estas páginas: una tarea que enriquece la gramática y su praxis con la integración de entornos digitales en los tradicionales. De esta forma se aproxima el texto en su diferentes manifestaciones (recuérdense el paisaje lingüístico urbano, las entradas de @elconejitoorgráfico o la web de Fundéu) de forma contextualizada y secuenciada (por acción y por evaluación) para propiciar la reflexión gramatical, puente para el desarrollo eficaz de las habilidades comunicativas (oral y escrita).

\section{Bibliografía}

Álvarez-Rosa, C. V. (2019a). El desarrollo de la competencia comunicativa oral como reto para la concienciación en la formación inicial de maestros. En M. Campos Fernández-Fígares y Mª . C. Quiles Cabrera (eds.) Repensando la didáctica de la lengua y la literatura. Paradigmas y líneas emergentes de investigación. Madrid: Visor, pp. 309-320.

Álvarez-Rosa, C. V. (2019b). 'Booktuber' como recurso para el desarrollo de la expresión oral en el aula de Secundaria. Material didáctico para la formación docente. En C. López Esteban (ed.) De la innovación a la investigación en las aulas. Salamanca: Ediciones Universidad de Salamanca, pp. 191-210.

Álvarez-Rosa, C. V. (2019c). Un paseo por la ciudad para comprender mejor las cuestiones lingüístico-discursivas del español actual. En Alves, D. et al. VIII Conferência Internacional Investigação, Práticas e Contextos em Educação. Leiria: ESECC-IPL, pp. 442-445. 
Álvarez-Rosa, C. V., V. J. Marcet Rodríguez y S. Ramos Ahijado (2018). A revisão como género discursivo inicial para a prática de escrever em estudantes universitários. En Alves, D. et al. VII Conferência Internacional Investigação, Práticas e Contextos em Educação. Leiria: ESECC-IPL, pp. 107-117.

Chestnut, M. et al. (2013). The language lessons around us: Undergraduate English Pedagogy and Linguistic Landscape Research. English Teaching: Practice and Critique, 12/2, pp. 102-120.

Estaire, S. y J. Zanón (1994). Planning Classwork. A task based approach. Handbooks for the English Classroom. Oxford: Heinemann.

Estaire, S. y J. Zanón (1990). El diseño de unidades didácticas mediante tareas: principios y desarrollo. Comunicación, lenguaje y educación, 7-8, pp. 54-90.

Gómez Torrego, L. (2011). Las normas académicas: últimos cambios. Madrid: SM.

Landry, R. y R. Y. Bourhis (1997). Lingüística Lnadscape and Ethnolinguistic Vitality: an Empirical Study, Journal of Language and Social Psychology, 16, pp. 23-49.

Lomas, C. (2014). La educación lingüística, entre el deseo y la realidad. Competencias comunicativas y enseñanza de la lengua. Barcelona: Octaedro.

Long, M. (1985). The Design of Classroom Second Language Acquisition: towards Taskbased Language Teaching. En Hyltenstam, K. y Pienemann, M. (eds.), Modelling and Asessing Second Language Acquisition. London: Multilingual Matters.

Malinowski, D. (2014). Linguistic landscape: new contexts, competences, and directions for the language classroom. Recuperado de: https://www.youtube.com /watch?v=5RiRZFw3VgY

Mantecón, B. (1989). Justificación de la gramática escolar. Cauce. Revista de Filología y su Didáctica, 12, pp. 59-92.

Nunan, D. (2011). La enseñanza de lenguas basada en tareas. Madrid: Edinumen.

Real Academia Española y Asociación de Academias de la Lengua Española (2013). Ortografía escolar de la lengua española. Madrid: Espasa.

Real Academia Española y Asociación de Academias de la Lengua Española (2011). Nueva gramática básica de la lengua española. Madrid: Espasa.

Real Decreto 1105/2014, de 26 de diciembre, por el que se establece el currículo básico de la Educación Secundaria Obligatoria y del Bachillerato.

Real Decreto 126/2014, de 28 de febrero, por el que se establece el currículo básico de la Educación Primaria.

Real Decreto 1630/2007, de 29 de diciembre, por el que se establecen las enseñanzas mínimas del segundo ciclo de Educación Infantil.

Richards, J., J. Platt y J. Weber, (1986). Longman Dictionary of Applied Linguistics. London, Longman.

Sayer, P. (2009). Using the linguistic landscape as pedagogical resource. ELT Journal, 64/2, pp. 143-155. 
Zanón, J. (coord.) (1999). La enseñanza del español mediante tareas. Madrid: Edinumen. Anexo 1

Banco de imágenes de la subtarea 1 (Fuente: elaboración propia)
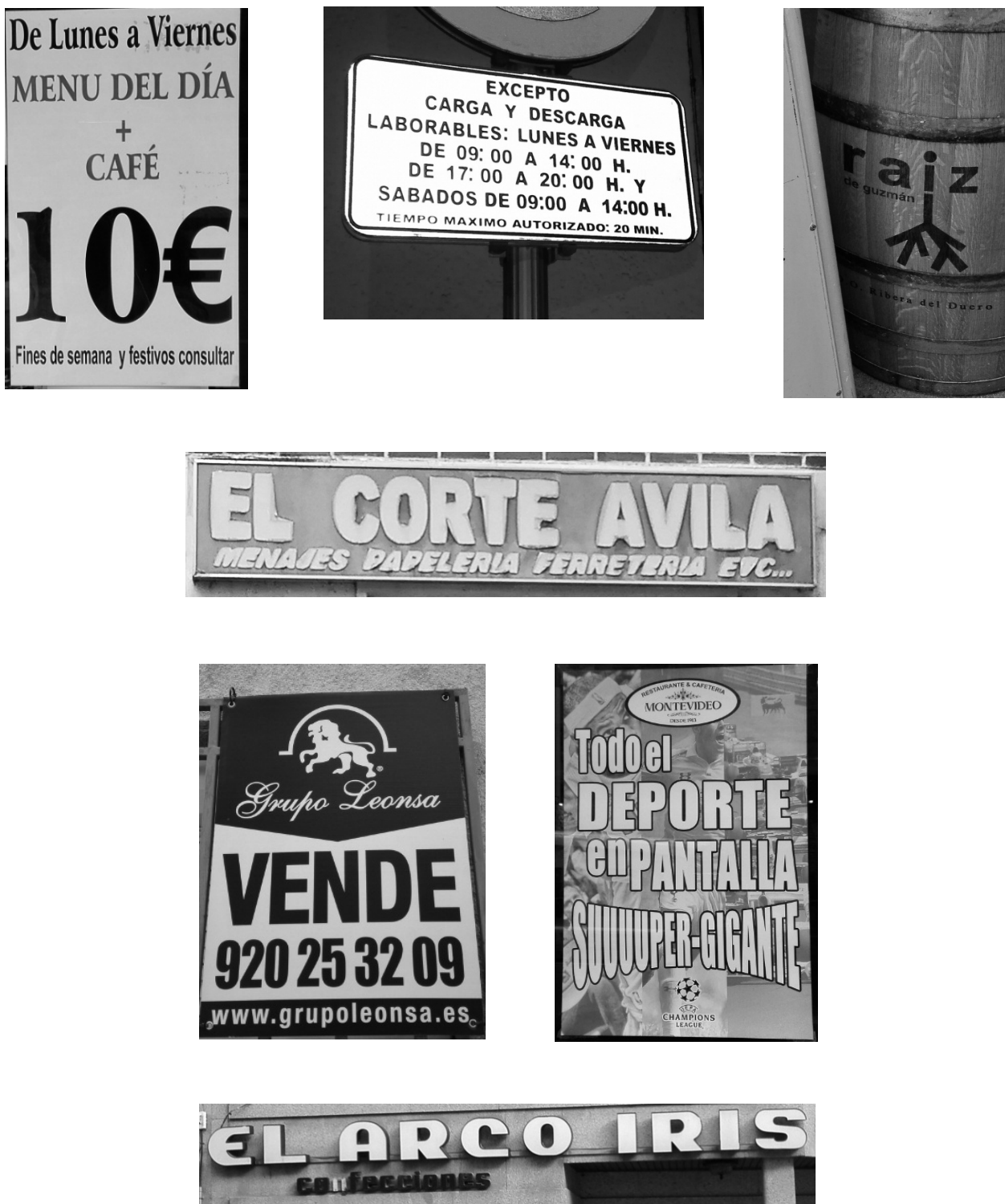


\section{Anexo 2}

\section{Enlaces referidos al movimiento Acción Ortográfica}

En Facebook podemos consultar las siguientes páginas:

https://cutt.ly/rrcW8jQ

https://cutt.ly/prcW4rF

https://cutt.ly/CrcEiwN

En Twitter: @AcciOrtografica, @AOrtografica, @ortograconejito

Instagram: @accionortografica, @elfilodelalogia, @letras_y_series, @elconejitoorgráfico Aplicación móvil: Escribir bien es de guapas

Yuldeacas: Acción Ortográfica Madrid, disponible en: https://cutt.ly/ZrcW9DI

Artículo de El Espectador "Conozca 'Acción Ortográfica', el corrector de las faltas de ortografía en grafitis callejeros", disponible en: https://cutt.ly/srcW2Qr 
